\title{
A spatial epidemiological analysis of nontuberculous mycobacterial infections in Queensland, Australia
}

\author{
Michael P Chou ${ }^{1,4^{*}}$, Archie CA Clements ${ }^{1}$ and Rachel M Thomson ${ }^{2,3}$
}

\begin{abstract}
Background: The epidemiology of infections with nontuberculous mycobacteria (NTM) has been changing and the incidence has been increasing in some settings. The main route of transmission to humans is considered to be from the environment. We aimed to describe spatial clusters of cases of NTM infections and to identify associated climatic, environmental and socio-economic variables.

Methods: NTM data were obtained from the Queensland Mycobacterial Reference Laboratory for the period 2001-2011. A Bayesian spatial conditional autoregressive model was constructed at the postcode level, with covariates including soil variables, maximum, mean and minimum rainfall and temperature, income (proportion of population earning $<\$ 32,000$ and $<\$ 52,000$ ) and land use category.

Results: Significant clusters of NTM infection were identified in the central Queensland region overlying the Surat sub-division of the Great Artesian Basin, as well as in the lower North Queensland Local Government Area known as the Whitsunday region. Our models estimated an expected increase of 21\% per percentage increase of population earning $<\$ 52,000$ (95\% Cl 9-34\%) and an expected decrease of 13\% for every metre increase of average topsoil depth for risk of Mycobacterium intracellulare infection (95\% Cl -3 - -22\%). There was an estimated increase of 79\% per $\mathrm{mg} / \mathrm{m}^{3}$ increase of soil bulk density (95\% Cl 26-156\%) and 19\% decrease for every percentage increase in population earning $<\$ 32,000$ for risk of $M$. kansasii infection ( $95 \% \mathrm{Cl}-3--49 \%)$.
\end{abstract}

Conclusions: There were distinct spatial clusters of M. kansasii, $M$. intracellulare and $M$. abscessus infections in Queensland, and a number of socio-ecological, economic and environmental factors were found to be associated with NTM infection risk.

Keywords: Nontuberculous mycobacteria (NTM), Mycobacterium intracellulare, Mycobacterium kansasii, Mycobacterium abscessus, Spatial epidemiology

\section{Background}

Nontuberculous mycobacteria (NTM) are ubiquitous in environments around the world. NTM have been isolated from soil, water and air as well as in more engineered contexts like water pipes, showerheads, bio-films and transgenic plants $[1,2]$. Interest in NTM has been gaining steadily over the past 20 years as associations between

\footnotetext{
* Correspondence: michael.chou@uq.net.au

${ }^{1}$ University of Queensland, Infectious Disease Epidemiology Unit, School of Population Health, Brisbane, Australia

${ }^{4}$ School of Population Health, University of Queensland, Level 2, Public

Health Building, Herston Road, Herston, QLD 4006, Australia

Full list of author information is available at the end of the article
}

NTM and HIV/AIDS, and NTM and structural lung diseases, have become better understood [3].

NTM incidence has been shown to be high in particular geographic regions and ecologies [4]. In Australia and the United States, NTM isolates are more common than Mycobacterium tuberculosis (TB) isolates. Incidence rates for NTM are estimated to be between 1.0-1.8 per 100,000 persons per year in developed countries [3]. HIV infection predisposes a host to NTM infection and the HIV epidemic has been an important contributor to increased incidence of NTM infections in developed countries [5].

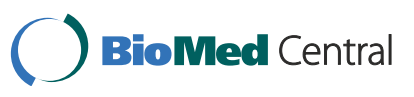

(c) 2014 Chou et al.; licensee BioMed Central Ltd. This is an Open Access article distributed under the terms of the Creative Commons Attribution License (http://creativecommons.org/licenses/by/2.0), which permits unrestricted use, distribution, and reproduction in any medium, provided the original work is properly credited. The Creative Commons Public Domain Dedication waiver (http://creativecommons.org/publicdomain/zero/1.0/) applies to the data made available in this article, unless otherwise stated. 
There remain areas of uncertainty in the characterisation of NTM epidemiology and pathogenicity because NTM contamination and colonisation from the environment is common and not necessarily harmful [6]. Furthermore, clinical reporting is often not uniformly standardised. Therefore, complete, high-quality epidemiological data on NTM infections are not always available. Fortunately, the Australian state of Queensland has had a mandatory reporting scheme for NTM infections since the introduction of a nationwide TB control campaign. All isolates of NTM throughout the state are recorded in a database, providing unique opportunities for epidemiological research.

With increasing availability of data online and accessibility of geographic information system (GIS) software and other mapping tools, spatial analytical techniques in epidemiology have become well established. Spatial methods have been employed in disease mapping, health surveillance and the development of spatial decision support systems [7]. Spatial analysis facilitates the identification of regions with high disease incidence and provides justification for more targeted investigations or interventions. A previous study examined spatial clusters of NTM infections in the United States (US) and identified higher income and education levels, higher evapotranspiration of surface water and higher copper and sodium soil levels as significant predictors of NTM infection risk [8]. This study from the U.S. supports the need to further investigate environmental predictors and spatial patterns of NTM in different settings.

The epidemiology of NTM infection is changing and refining the understanding of disease predictors will better inform clinical and public health efforts to control the disease. This paper aims to identify spatial patterns of NTM infections in Queensland between 2001 and 2011, and the association between NTM infection risk and a range of climate, environmental, demographic and socio-economic variables.

\section{Methods}

\section{Study area}

Queensland is located in the northeast of Australia between the latitudes of $10^{\circ} \mathrm{S}$ and $28^{\circ} \mathrm{S}$ and longitudes of $138^{\circ} \mathrm{E}$ and $153^{\circ} \mathrm{E}$. The population of Queensland is 4.6 million people, and the state is administratively divided into 74 local government areas and 423 postcodes. Key industries include tourism, agriculture and mining. Climactically, northern Queensland is tropical and southern Queensland is sub-tropical. Most of the state experiences two distinct weather seasons: a warm summer with higher rainfall and a mild winter with lower rainfall.

\section{Ethical clearance}

The project was approved by the Research Ethics committee of the University of Queensland (Project number
2012000471) in accordance with the provisions contained in the National Statement on Ethical Conduct in Human Research.

\section{Data sources}

\section{Nontuberculous mycobacterial infection data}

All public hospital patient specimens for which mycobacterial culture is requested are forwarded to the Queensland Mycobacterial Reference Laboratory (QMRL). Requests in the private sector are processed by two main laboratories (providing $>90 \%$ of the private mycobacterial pathology service in the state) and a few smaller laboratories. The two main private laboratories identify mycobacteria in specimens and, if detected, report them as "Atypical mycobacteria, not further specified". Subsequent to culture, not all isolates are forwarded to the QMRL for species identification. However, the private laboratories do send isolates when (i) the specimen is smear positive (to exclude TB), (ii) the specimen is a bronchial washing or was obtained from a site other than sputum, (iii) there is more than one specimen positive for that patient, or (iv) at the request of the treating clinician. The majority of nonpulmonary isolates grown by private laboratories are sent to the QMRL for speciation. Hence, all speciated and the majority of unspeciated NTM are included in the database of the QLD TB control centre.

In terms of the specific laboratory methodology, human samples were digested and decontaminated using 4\% $\mathrm{NaOH}$, neutralised with phosphoric acid and centrifuged at $3000 \mathrm{~g}$ to concentrate the acid-fast bacilli (AFB). Smears were prepared from the sediment and stained by the Ziehl-Niehlsen (ZN) method. One Lowenstein-Jensen slope (pyruvate) and $7 \mathrm{ml}$ Mycobacterial Growth Indicator Tube (MGIT) were inoculated and incubated at $35^{\circ} \mathrm{C}$ until growth was detected. ZN staining of colonies confirmed AFB. Multiplex PCR was performed to discriminate between $M$. tuberculosis, $M$. avium, M. intracellulare, $M$. abscessus and other Mycobacterium spp [9]. Isolates identified as other Mycobacterium spp were further speciated using Hain Life Sciences GenoType Mycobacterium AS (additional species) kit (2004-7 only) and/or 16S rRNA sequencing in conjunction with phenotypic characteristics.

For this study, all notified isolates from 2001-2011 were retrieved for analysis. In the case of multiple cultures per patient, only one isolate per calendar year was included, unless multiple species were identified. In this way, a reasonable balance may be achieved between capturing the environmental burden of strain types with the over-representation of patients with relapsed or persistent disease. For those with the same species - mainly $M$. intracellulare - it has been shown that most cases of subsequent isolation of MAC in individual patients represent reinfection with different strains, as opposed to relapse. [10] Age at time of positive isolate, gender and 
residential address were retrieved from de-identified records in the QTBCC database.

\section{Demographic and environmental data}

Income data were obtained from the 2010-11 Australian Bureau of Statistics [11]. The income variables percentage $<\$ 32000$ and percentage $<\$ 52000$ (of annual income) were based on the classifications of the Australian Bureau of Statistics. Percentage $<\$ 32000$ reflected relative disadvantage and $<\$ 52000$ is related to the average annual income of $\$ 51923$ for Australians in 2010-11. Indigenous and labour data were obtained from the Office of Economic and Statistical Research [12]. Thirty arcsecond resolution raster data for maximum, minimum and mean temperature and rainfall were obtained from the WorldClim database [13]. Data on soil characteristics (permeability, depth, drainage, $\mathrm{pH}$, nitrogen, phosphorus, bulk density, and composition), with a $1 \mathrm{~km}$ resolution, were obtained from the Commonwealth Scientific and Industrial Research Organisation (CSIRO) Australian Soil Resource Information System [14]. Layer A (surface layer, or topsoil) variables were used because this layer interfaces directly with human contact and activity. Soil composition classification data were refined for categorical analysis into their predominant base soil types - sand, clay, peat and loam. Landuse data were obtained from the national scale land use version 4 data (2005-2006) of the Australian Collaborative Landuse and Management Program (ACLUMP) [15]. Landuse was classified using six broad categories: conservation and natural environments; grazing vegetation and forestry production; dryland agriculture and plantations; irrigated agriculture and plantations; intensive uses/industry; and water.

Each of the demographic and environmental variables was summarized by postcode. For the environmental variables available in raster format, this involved extracting the mean value of the pixels that fell within the polygon that defined the boundary of the postcode. Extractions were done using the geographical information system (GIS) software ArcGIS (version 10.1).

\section{Statistical analysis}

For selected species of NTM (M. abscessus, M. avium, M. chelonae, M. fortuitum, M. gordonae, M. intracellulare, M. kansasii), age and sex-adjusted standardised morbidity ratios (SMR) were calculated by postcode. Pairwise Spearman's correlation coefficients were calculated for each pair of continuous predictor variables, and if the correlation coefficient was $>0.9$, the variable with the highest $\mathrm{p}$-value in a bivariate Poisson regression model was excluded from further analysis.

For each of the selected species of NTM, the number of cases recorded by postcode during 2001-2011 was denoted as the dependent variable in an initial Poisson regression analysis, conducted using the statistical software package Stata version 11.2 (Statacorp, College Station, Texas). The expected number of cases for each postcode, adjusted for the age (categorised as $<65$ years and $\geq 65$ years) and sex distribution of each postcode (using 2011 census data from the Australian Bureau of Statistics), was calculated, and entered into the models as an offset. Saturated models were created using all of the demographic and environmental variables as covariates (excluding the collinear variables) and an iterative, backwards stepwise method was used to reduce the set of covariates to those that were significantly associated with the dependent variable $(p<0.05)$.

Following covariate selection, Poisson and zero-inflated Poisson models were compared using the Akiake Information Criterion and Vuong Statistic (notably, at least 30\% of the postcodes for each NTM species had zero incidence). Based on the model results, the standard form of Poisson regression was adopted for subsequent analyses.

For each NTM species, three mixed-effects Poisson regression models were created in a Bayesian framework using the statistical software WinBUGS (version 1.43). The first model (Model I) included the selected covariates with an unstructured postcode-level random effect. The second model (Model II) included the selected covariates with a spatially structured random effect. The third model (Model III), a convolution model, included the covariates and both the unstructured and spatially structured random effects.

Because a different set of covariates was used for each NTM species, the following shows a generalised form of Model III with $n$ predictor variables, under the assumption that the observed counts of each NTM species $\left(Y_{i}\right)$ for the $i$ th postcode followed a Poisson distribution, with mean $\mu$ :

$$
\begin{aligned}
& Y_{i} \approx \operatorname{Poisson}\left(\mu_{i}\right) \log \left(\mu_{i}\right)=\log \left(E_{i}\right)+\theta_{i} \theta_{i} \\
&=\alpha+\beta_{1}\left(\text { Variable }_{1_{i}}\right) \\
&+B_{2}\left(\text { Variable }_{2_{i}}\right)+\ldots \\
&+B_{n}\left(\text { Variable }_{n_{i}}\right)+w_{i}+s_{i}
\end{aligned}
$$

where $E_{i}$ is the age and sex-adjusted expected number of cases in postcode $i, \alpha$ represents the intercept, $\beta_{1} \ldots \beta_{\mathrm{n}}$, are the coefficients for the covariates, $w_{i}$ are the unstructured random effects, with a mean of zero and variance $\sigma_{w}^{2}$ and $s_{i}$ are the spatially structured random effects, with a mean of zero and variance $\sigma_{s}^{2}$. Models I and II simply excluded $s_{i}$ and $w_{i}$ respectively.

Priors for the spatially structured random effects were derived using an intrinsic conditional autoregressive (CAR) modelling structure with an adjacency weights matrix of the postcodes. The adjacency matrix was constructed using the maps2WinBUGS plugin (version 2.2) of Quantum GIS (QGIS Wroclaw, version 1.73); postcode 
pairs that were neighbours were given a weight of 1 and postcode pairs that were not neighbours were given a weight of 0 . Priors for the coefficients were assumed to have normal distributions (with mean $=0$ and 1 /variance $=$ $\left.1 \times 10^{-4}\right)$. A flat prior (i.e. an unbounded uniform distribution) was adopted for the intercept. The variance parameters for the random effects were assumed to have inverse gamma distributions, with shape and scale parameter values of 0.5 and 0.005 respectively.

A Bayesian imputation approach was employed to account for missing data among the covariates. There were at most two missing values from each set of 423 values (per variable). All variables with missing values were related to soil or landuse. Missing values were included as random variables. For the categorical covariates (included in the model as binary dummy variables), the random variables were assumed to have a Bernoulli distribution with a uniform prior ranging from 0 to 1 , while missing continuous data were assumed to have a normal distribution with non-informative priors for both the mean and precision.

Using the Bayesian approach, posterior distributions for the random variables were estimated using Markov chain Monte Carlo simulation with Gibbs sampling employed by WinBUGS. Models were run with two chains. The initial 3000 iterations of the chains were discarded as burn in. Posterior kernel densities and history plots were visualised to assess for convergence and mixing. The models were subsequently thinned as appropriate based on inspection of autocorrelation plots. Depending on the factor for thinning, the chains were run until 20,000 samples were obtained for parameter estimation once convergence was observed. The Deviance Information Criterion (DIC) for each model was also monitored for model comparison and selection.

\section{Results}

Over the 10-year period, there were a total of 6,599 NTM isolate notifications. Table 1 shows descriptive statistics for the most frequently isolated NTM species.
The seven species that were most frequently isolated were selected for analysis. $M$. intracellulare accounted for nearly $35 \%$ of the NTM isolates. Isolates from extrapulmonary sites comprised $19.6 \%$ of isolates. Only in $M$. fortuitum and $M$. chelonae was the count higher in extrapulmonary than pulmonary sites. Maps of the SMRs for each NTM species by postcode are shown in Figure 1. Total counts were presented because previous studies have demonstrated no evidence that the strains causing pulmonary and extrapulmonary disease are different [16]. Each species of NTM showed distinct spatial patterns.

For four NTM species - M. abscessus, M. avium, $M$. intracellulare and M. kansasii - the models with the best fit (as determined using the DIC) included Models II and III - those with a spatially structured component, with Model III having the best fit for $M$. intracellulare and $M$. kansasii and Model II having the best for M. abscessus and $M$. avium. This indicated that risk of infection with these four NTM species demonstrated significant spatial heterogeneity after accounting for the covariates in the models. Furthermore, of these four species, significant covariates (soil depth, soil bulk density, earning $<\$ 52,000$ and earning $<\$ 32,000)$ were found for $M$. intracellulare and M. kansasii (Table 2).

Among the other NTM species where the models did not support evidence of spatial heterogeneity (i.e. where the lowest DIC was associated with Model I), soil pH was identified as a significant predictor variable for $M$. fortuitum (RR 21\%; 95\% CI 1-45\%) and soil nitrogen content was found to be a significant predictor variable for $M$. chelonae (RR 24\%; 95\% CI 3-50\%).

Risk of $M$. intracellulare infection was estimated to increase by $21 \%$ per percentage increase of population earning under $\$ 52,000$ and to decrease by $13 \%$ for every metre increase of topsoil depth. Risk of $M$. kansasii infection was estimated to increase by $79 \%$ per $\mathrm{mg} / \mathrm{m}^{3}$ increase of soil bulk density and to decrease by $19 \%$ for every percentage increase in population earning under $\$ 32,000$.

Table 1 Descriptive statistics for NTM isolates from 2001-2011

\begin{tabular}{|c|c|c|c|c|c|c|}
\hline \multirow[t]{2}{*}{ Species } & \multicolumn{3}{|c|}{ Count } & \multirow{2}{*}{$\begin{array}{c}\text { Proportion } \\
\text { of all } \\
\text { isolates }\end{array}$} & \multirow{2}{*}{$\begin{array}{c}\text { Mean } \pm \\
\text { SD (per } \\
\text { postcode) }\end{array}$} & \multirow[t]{2}{*}{ Range } \\
\hline & Total & Pulmonary & Extra- pulmonary & & & \\
\hline M. intracellulare & 2,306 & 2,184 & 122 & $34.9 \%$ & $5.50 \pm 7.76$ & $0-63$ \\
\hline M. avium & 674 & 599 & 75 & $10.2 \%$ & $1.50 \pm 2.72$ & $0-16$ \\
\hline M. fortuitum & 493 & 195 & 298 & $7.5 \%$ & $1.10 \pm 1.92$ & $0-13$ \\
\hline M. abscessus & 489 & 334 & 155 & $7.4 \%$ & $1.16 \pm 2.01$ & $0-17$ \\
\hline M. kansasii & 188 & 174 & 14 & $2.8 \%$ & $0.45 \pm 1.17$ & $0-15$ \\
\hline M. chelonae & 183 & 64 & 119 & $2.8 \%$ & $0.43 \pm 0.95$ & $0-9$ \\
\hline M. gordonae & 162 & 146 & 16 & $2.5 \%$ & $0.39 \pm 0.81$ & $0-6$ \\
\hline Other & 1,357 & 909 & 448 & $20.6 \%$ & $2.40 \pm 3.61$ & $0-34$ \\
\hline Unspeciated & 747 & 703 & 44 & $11.3 \%$ & $2.39 \pm 3.59$ & $0-31$ \\
\hline Total & 6,599 & 5308 & 1291 & $100.0 \%$ & $2.55 \pm 4.96$ & $0-63$ \\
\hline
\end{tabular}



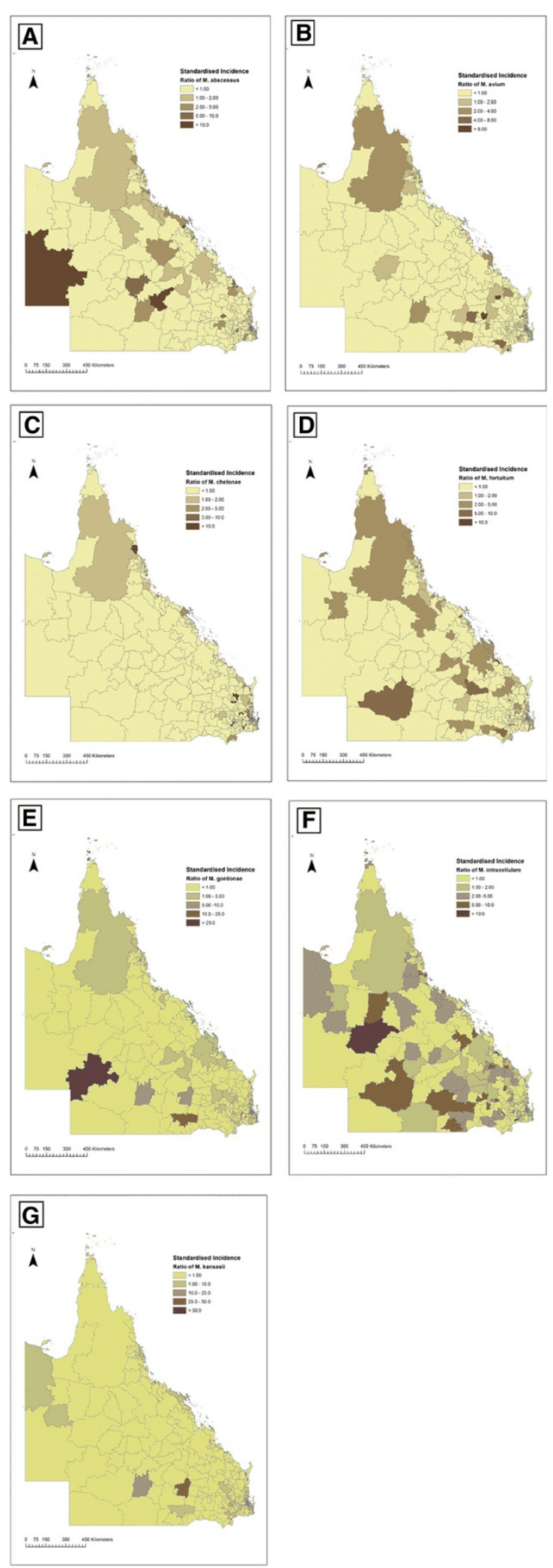

Figure 1 The standardised incidence ratio for seven NTM species. Standardised incidence ratios of M. abscessus (A), M. avium (B), M. chelonae (C), M. fortuitum (D), M. gordonae (E), M. intracellulare (F) and M. kansasii (G) from 2001-2011 mapped by postcode for Queensland, Australia. 
Table 2 Modelling results for $M$. intracellulare and $M$. kansasii

\begin{tabular}{|c|c|c|c|c|}
\hline \multirow{2}{*}{$\begin{array}{l}\text { Model III } \\
\text { Variables }\end{array}$} & \multicolumn{2}{|c|}{ M. intracellulare } & \multicolumn{2}{|c|}{ M. kansasii } \\
\hline & Posterior mean \pm SD & RR $(95 \% \mathrm{Cl})$ & Posterior mean \pm SD & $\mathrm{RR}(95 \% \mathrm{Cl})$ \\
\hline Intercept (a) & $-0.021 \pm 0.014$ & & $-0.84 \pm 0.37$ & \\
\hline Soil Depth (m) & $-0.13 \pm 0.06$ & $0.87(0.78-0.97)$ & & \\
\hline Earning $<\$ 52000$ & $0.19 \pm 0.05$ & $1.21(1.09-1.34)$ & & \\
\hline Soil Bulk Density $\left(\mathrm{mg} / \mathrm{m}^{3}\right)$ & & & $0.58 \pm 0.18$ & $1.79(1.26-2.56)$ \\
\hline Earning $<\$ 32000$ & & & $-0.34 \pm 0.16$ & $0.71(0.51-0.97)$ \\
\hline Heterogeneity s (structured) & $0.46 \pm 0.12$ & & $1.57 \pm 0.65$ & \\
\hline Heterogeneity $w$ (unstructured) & $0.03 \pm 0.03$ & & $0.13 \pm 0.20$ & \\
\hline DIC & \multicolumn{2}{|c|}{6451.81} & \multicolumn{2}{|c|}{10123.70} \\
\hline
\end{tabular}

Figure 2 has four chloropleth maps that show the spatially-structured relative risk of $M$. intracellulare, $M$. kansasii, M. abscessus and M. avium. Each map shows the risk of each NTM species relative to no disease that may be attributed to spatial factors in the environment. Effectively, the maps identify 'hotspots' in the state. Clusters of high relative risk for $M$. intracellulare and $M$. kansasii were found in the Darling Downs region of south central Queensland. The cluster for M. kansasii was more geographically focused around the town of Roma. Notably, the relative risk was 75 times higher than the average $(\mathrm{p}<0.05)$ for $M$. kansasii in the postcodes containing the towns of Clifford and Yuleba, nearby to Roma. There was also a cluster of high relative risk for $M$. abscessus in the Whitsunday region of Queensland.

The estimated variance of the spatial component was $0.46 \pm 0.12,1.57 \pm 0.65$ and $0.64 \pm 0.18$ for $M$. intracellulare, M. kansasii and M. abscessus respectively. This was comparatively larger than the variance of the unstructured components in these models, indicating that residual risk, after accounting for the covariates, was predominantly spatially structured.

\section{Discussion}

Three clusters of postcodes with high risk for specific NTM infections were found in two distinct regions of Queensland. In addition, multivariate Bayesian analysis identified significant predictors of NTM risk, including socioeconomic and environmental factors, for four NTM species.

Geographically, the clusters of $M$. intracellulare and M. kansasii were located in a region overlying the Surat Division of the Great Artesian Basin. Interestingly, the western geologic border of the Surat Basin corresponds well with the western edge of the $M$. intracellulare cluster. This region is well known for its agricultural and mining activities with a number of developed petroleum and coal seam gas wells. In addition, the water supply for many communities in the region is primarily from private and communal bores, aquifers and rainwater tanks. It is difficult to ascertain the exact number and distribution of these water sources. However, Figure 3 shows the percentage of water in each region that is stored in large dams [17]. By inference, suburban households in areas surrounding these dams are more likely to source water from reticulated supplies rather than private bores.

There are several potential explanations for the significantly higher relative incidence of $M$. kansasii in the Yuleba and Clifford areas. Yuleba is a small town and the site of a major processing facility for silica deposits. Silicosis has been identified as a host susceptibility factor for M. kansasii. Moreover, mining activity is common in the Maranoa-Balonne region (the broader administrative area that includes Yuleba and Clifford). There have been several studies linking $M$. kansasii to industrial activities such as gold mining and iron manufacture in South Africa, Japan and the former Czechoslovakia [18-20]. In the study by Corbett and Hay, new pulmonary cavitations from $M$. kansasii were more likely to be found in miners with previous TB scarring or silicosis. In addition, Yuleba has had a reticulated supply from bore water since the 1960s. M. kansasii has been identified as a cause of opportunistic infections from drinking water distribution systems [21-23]. Nonetheless, while $M$. kansasii has been found in potable water supplies in the greater Brisbane metropolitan area [2], relatively few strains match clinical isolates from patients [24,25].

The evidence linking reticulated water as a source of infection with $M$. intracellulare is scant [25,26]. As sequencing technologies have become more refined, $M$. intracellulare previously identified in water and biofilm samples have actually been found to be $M$. chimaera. In fact, older studies from QLD have found $M$. intracellulare in soil, house dust and rainwater tanks $[27,28]$. Synthesizing these perspectives, transmission of $M$. intracellulare may be more related to dust inhalation or direct ground water contamination by soil. Contamination during runoff events is also possible and this has been previously postulated as a potential mechanism for another species 

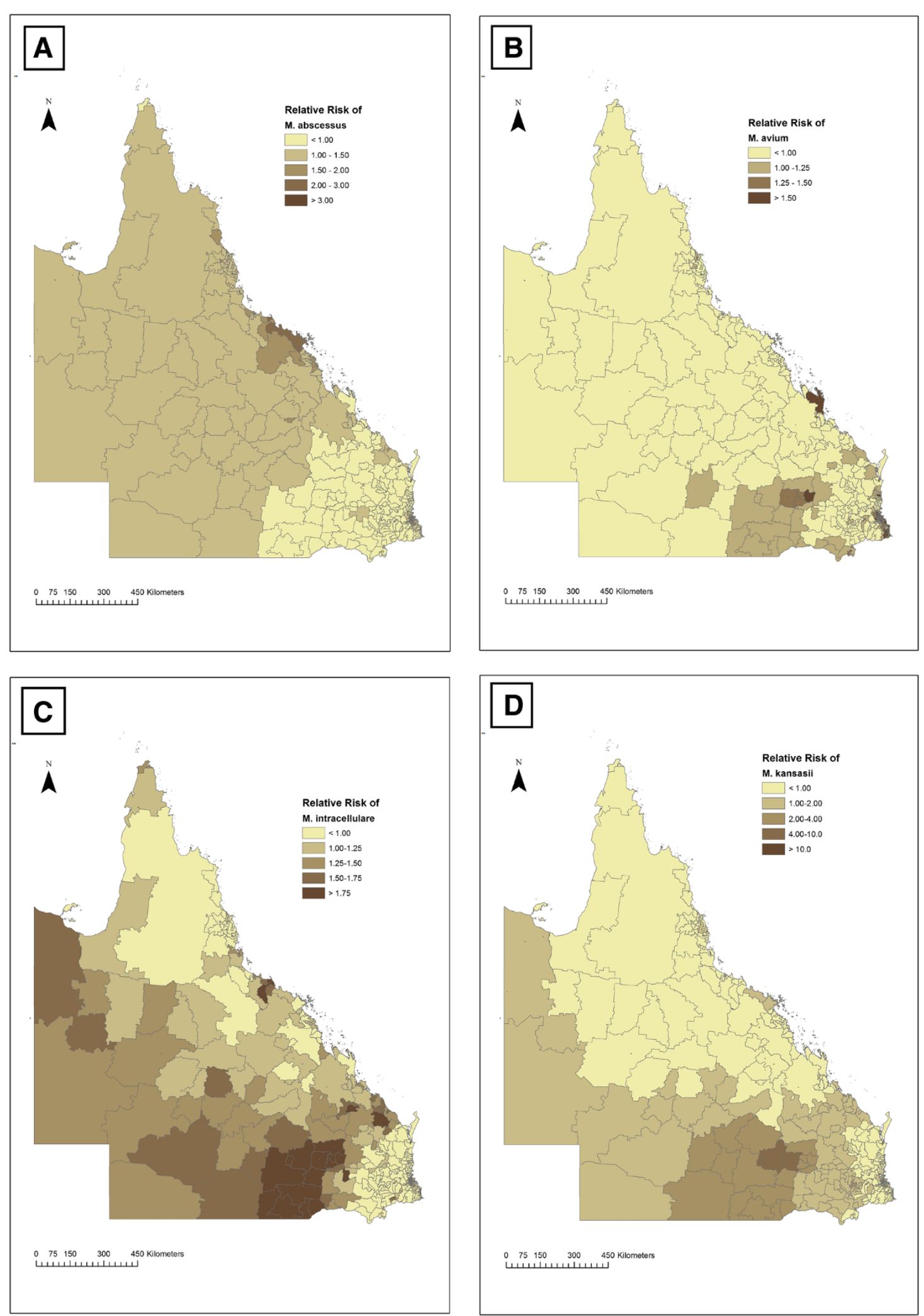

Figure 2 The relative risk for four NTM species. The relative risk for M. abscessus (A), M. avium (B), M. intracellulare (C), M. kansasii (D) from 2001-2011 mapped by postcode for Queensland, Australia. 


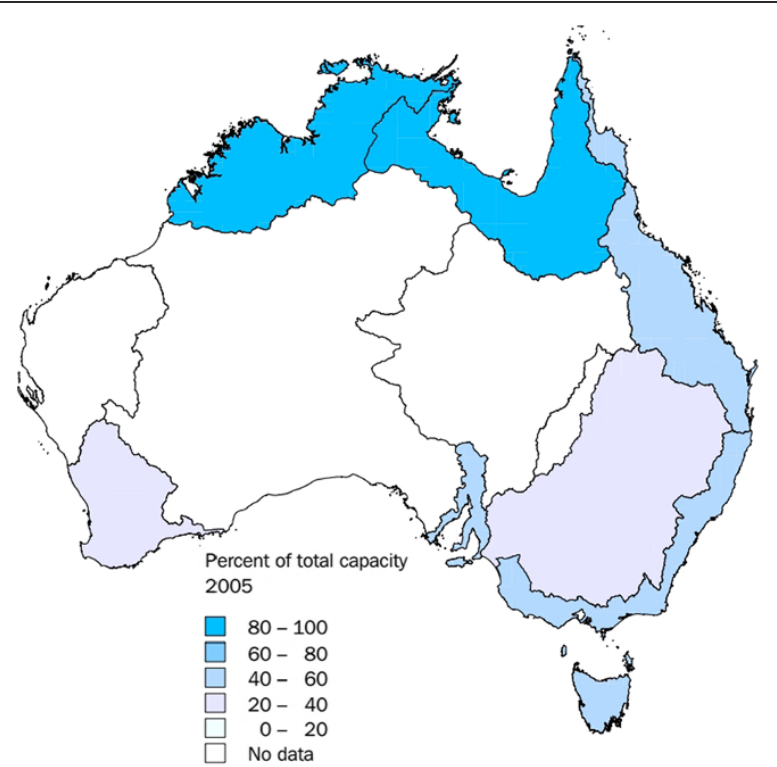

Figure 3 Percent of total water capacity stored in large dams for each drainage division [17]. Proportion of water stored in large dams for each Australian drainage divisions in 2005.

of NTM [29]. The co-incidence of high relative risk in Yuleba for both M. kansasii and M. intracellulare may indicate common routes of exposure potentially mediated through inhalation of dust or fine soil particles or contamination of water by these two species.

The last report relating $M$. kansasii to soil appears to have been published over 40 years ago [30]. More recently, an association was reported between $M$. intracellulare and anaerobic soils [31,32]. Another possible route of NTM transmission in the Maranoa region, where there is greater reliance on tank and bore water, is soil contamination of water sources. Here we found that risk of $M$. intracellulare infection was correlated with a shallower soil depth. Potential reasons may include the poor rooting of vegetation in shallow soil, leading to decreased uptake of soil nutrients, leaving a nutrient rich topsoil environment in which mycobacteria may thrive [33]. Another reason may be human activities related to shallow soil in agricultural regions such as the Darling Downs. A shallow soil depth is usually associated with low Plant Available Water Capacity (PAWC) and low crop yields [34]. To improve yields, soil is often disturbed in a process called "deep ripping". This activity may aerosolise soil particles. Conversely, another potential response to improve crop yields in shallow soils is liming - this may actually inhibit mycobacteria growth as it increases acidity. Liming can be done before, during or after deep ripping.

Soil bulk density, found to be associated with risk of $M$. kansasii infection, is the dry weight of soil per $\mathrm{m}^{3}$ of soil volume. This variable can be affected by a number of other soil factors such as permeability, composition and depth. Like soil depth, soil bulk density is affected by human activity. Notably, soil bulk density can be increased by constant or inappropriate tilling as well as by compressive forces from heavy agricultural machinery [35]. These activities may also increase the risk of mycobacteria exposure from soil. Increased bulk density impairs root growth, further contributing to nutrient rich topsoil environments that are conducive to mycobacterial growth [33]. Peat soil composition was found to be a predictor of NTM risk in other studies but this is unlikely to be the case in Australia, because peat soil is only found in sparse Alpine regions of Australia [36,37].

The variable for proportion of population earning $<\$ 32,000$ may be considered a representative indicator of socioeconomic status of the postcode. The finding of an increased relative risk for $M$. kansasii infection in postcodes with a higher socioeconomic status is consistent with the literature comparing NTM and socioeconomic determinants [38]. The positive correlation between $M$. intracellulare and proportion of the population earning $<\$ 52,000$ is harder to interpret. There are a number of potential confounders of this association, including smoking, alcohol intake and likelihood of seeking medical attention, that need to be considered.

The cluster of $M$. abscessus in the Whitsunday region requires further investigation. The region is well known for its tropical climate and pristine marine environments, and is a popular tourist destination. Isolates of $M$. abscessus from swimming pools and rainwater tanks have been linked to patient isolates in Brisbane [39]. Jacobs et al [40] associated water characteristics in a coastal lagoon with NTM. They found positive correlations with water 
temperature, nitrogen and phosphorus content and negative correlations with depth and salinity. Soil nitrogen and phosporus content was not associated with $M$. abscessus in our analysis.

While individual mycobacterial species have their own preferred growth environments [41], the lack of consistency in significant predictor variables across the seven NTM species analysed highlights the differing epidemiology of these organisms. Using aggregated NTM data by postcode over a 10 year period may have masked associations between NTM and environmental, climate and socioeconomic variables at finer spatial and temporal resolutions. The artificial nature of postcode boundaries may also have affected observed associations and spatial patterns, and might have given rise to ecological fallacy, whereby associations observed at the scale of the postcode do not reflect the association between exposure of individuals to a risk factor and their resultant risk of infection $[42,43]$.

Furthermore, identification of important predictors is also likely to be made more challenging by the multi-year latency periods of slow growing NTM species. Changing climactic conditions in Queensland add an additional layer of complexity: the 10-year period of the study has been Australia's hottest decade on record [44]. In Queensland, it was marked by severe drought conditions culminating in statewide water restrictions. This was followed by the wettest year on record in 2010, with significant flooding occurring twice that year. The first flood occurred in the central QLD regions where clusters of NTM have been identified. The second flood affected the state more widely. This complexity makes any analysis of secular trends during this period difficult to interpret. Finally, issues such as the presence of petroleum wells identified in our analyses require further investigation.

\section{Conclusions}

Distinct spatial clusters of M. kansasii, M. intracellulare and M. abscessus were identified in regions that contribute to Australia's agricultural, mining and tourism industries. Additionally, a number of socioecological, economic and environmental factors were found to be associated with NTM infection risk. A better understanding of the epidemiology of NTM infections could form the basis of cost-effective and targeted public health initiatives for the control of this disease in Australia and globally.

\section{Competing interests}

All of the authors declare no financial, professional, or otherwise personal interest of any nature or kind in any related product, service, and/or company.

\section{Authors' contributions}

ACAC conceived and designed the study. RMT was involved in the clinical data collection. MPC prepared datasets and statistical analyses. MPC drafted the manuscript and all authors contributed substantially to the revision of the manuscript. All authors read and approved the final manuscript.

\section{Acknowledgements}

MPC would like to thank Kelly Bryant from the Department of Science, Information Technology, Innovation and the Arts for her assistance in supplying the ASRIS database.

\section{Author details}

${ }^{1}$ University of Queensland, Infectious Disease Epidemiology Unit, School of Population Health, Brisbane, Australia. ${ }^{2}$ Gallipoli Medical Research Centre, Greenslopes Private Hospital, Brisbane, Australia. ${ }^{3} \mathrm{CHRISP}-\mathrm{TB}$, Queensland Health, Brisbane, Australia. ${ }^{4}$ School of Population Health, University of Queensland, Level 2, Public Health Building, Herston Road, Herston, QLD 4006, Australia.

Received: 17 January 2014 Accepted: 6 May 2014 Published: 21 May 2014

\section{References}

1. Hruska K, Kaevska M: Mycobacteria in water, soil, plants and air: a review. Vet Med 2012, 57:623-679.

2. Thomson R, Carter R, Tolson C, Coulter C, Huygens F, Hargreaves M: Factors associated with the isolation of nontuberculous mycobacteria (NTM) from a large municipal water system I Brisbane, Australia. BMC Microbiol 2013, 13:89. doi: 10.1186/1471-2180-13-89.

3. Griffith D, Aksamit T, Brown-Elliott B, Catanzaro A, Daley C, Gordin F, Holland SM, Horsburgh R, Huitt G, lademarco MF, Iseman M, Olivier K, Ruoss S, von Reyn CF, Wallace RJ Jr, Winthrop K, ATS Mycobacterial Diseases Subcommittee; American Thoracic Society; Infectious Disease Society of America: An official ATS/IDSA statement: diagnosis, treatment, and prevention of nontuberculous mycobacterial diseases. Am J Respir Crit Care Med 2007, 175:367-416

4. Hoefsloot W, Van Ingen J, Andrejak C, Angeby K, Bauriaud R, Bemer P, Beylis N, Boeree MJ, Cacho J, Chihota V, Chimara E, Churchyard G, Cias R, Dasa R, Daley $C L$, Dekhuijzen PNR, Domingo D, Drobniewski F, Esteban J, Fauville-Dufaux M, Folkvardsen DB, Gibbons N, Gómez-Mampaso E, Gonzalez R, Hoffmann H, Hsueh PR, Indra A, Jagielski T, Jamieson F, Jankovic $M$, et al: The geographic diversity of nontuberculous mycobacteria isolated from pulmonary samples: A NTM-NET collaborative study. Eur Respir J 2013, 42:1604-1613.

5. Porter J: Mycobacteriosis and HIV infection: the new public health challenge. J Antimicrob Chemother 1996, 37(Supp B):113-120.

6. Thomson R: Changing epidemiology of pulmonary nontuberculous mycobacteria infections. EID 2010, 16:1576-1583.

7. Kelly G, Seng C, Donald W, Taleo G, Nausien J, Batarii W, lata H, Tanner M, Vestergaard LS, Clements AC: A spatial decision support system for guiding focal indoor residual spraying interventions in a malaria elimination zone. Geospat Health 2011, 6:21-31.

8. Adjemian J, Olivier KN, Seitz AE, Falkinham III, Holland SM, Prevots DR: Spatial clusters of nontuberculous mycobacterial lung disease in the United States. Am J Respir Crit Care Med 2012, 186(6):553-558.

9. Wilton S, Cousins D: Detection and identification of multiple mycobacterial pathogens by DNA amplification in a single tube. $P C R$ Meth Appl 1992, 4:269-273.

10. Wallace JRJ, Brown-Elliott BA, McNulty S, Philley JV, Killingley J, Wilson RW, York DS, Shepherd S, Griffith DE: Macrolide/azalide therapy for nodular/ bronchiectatic: Mycobacterium avium complex lung disease. Chest J 2014. online ahead of print. doi:10.1378/chest.13-2538.

11. ABS: 2011 Census data. ; 2011 [online] Available at: http://www.abs.gov.au/ websitedbs/censushome.nsf/home/data?opendocument\&navpos $=200$ [Accessed: 12 Nov 2013].

12. OESR: Home page: Government Statistician, Queensland Treasury and Trade. 2006 [online] Available at: http://www.oesr.qld.gov.au/ [Accessed: 12 Nov 2013].

13. Hijmans $R$, Cameron $S$, Parra J, Jones $P$, Jarvis A: Very high resolution interpolated climate surfaces for global land areas. Int J Climatol 2005, 25:1965-1978

14. ASRIS: Untitled. ; 2007 [online] Available at: http://www.asris.csiro.au/ mapping/viewer.htm, State of Queensland (Department of Science, Information Technology, Innovation and the Arts) [Accessed: 12 Nov 2013]. 
15. ACLUMP: Land Use and Management Information for Australia. 2006 [online] Available at: http://www.daff.gov.au/abares/aclump [Accessed: 12 Nov 2013].

16. Thomson RM, Tolson CE, Carter R, Huygens F, Hargreaves M: Heterogeneity of clinical and environmental isolates of Mycobacterium fortuitum using repetitive element sequence-based PCR: municipal water an unlikely source of community-acquired infections. Epidemiol Infect 2014a. online ahead of print CJO2014. doi:10.1017/S0950268813003257.

17. Geosciences Australia: Applying geoscience to Australia's most important challenges - Geoscience Australia. ; 2005 [online] Available at: http://www.ga. gov.au/ [Accessed: 12 Nov 2013].

18. Corbett E, Hay M, Churchyard G, Herselman P, Clayton T, Williams BG, Hayes R, Mulder D, De Cock KM: Mycobacterium kansasii and M. scrofulaceum isolates from HIV-negative South African gold miners: incidence, clinical significance and radiology. Int J Tubercul Lung Dis 1999, 3:501-507.

19. linuma Y, Ichiyama S, Hasegawa Y, Shimokata K, Kawahara S, Matsushima T: Large-restriction-fragment analysis of Mycobacterium kansasii genomic DNA and its application in molecular typing. J Clin Microbiol 1997, 35:596-599.

20. Kubin M, Svandova E, Medek B, Chobot S, Vsovsk Y: Mycobacterium kansasii infection in an endemic area of Czechoslovakia. Tubercle 1980, 61:207-212.

21. Adrados B, Julian E, Codony F, Torrents E, Luquin M, Morat J: Prevalence and concentration of non-tuberculous mycobacteria in cooling towers by means of quantitative PCR: a prospective study. Curr Microbiol 2011, 62(1):313-319.

22. Santos R, Oliveira F, Fernandes J, Gonalves S, Macieira F, Cadete M: Detection and identification of mycobacteria in the Lisbon water distribution system. Water Sci Technol 2005, 52:177-180

23. Vaerewijck M, Huys G, Palomino J, Swings J, Portaels F: Mycobacteria in drinking water distribution systems: ecology and significance for human health. FEMS Microbiol Rev 2005, 29:911-934.

24. Thomson R, Tolson C, Huygens F, Hargreaves M: Strain variation amongst clinical and potable water isolates of $M$. kansasii using automated repetitive unit PCR. Int J Med Microbiol 2014, 304:484-489.

25. Thomson R, Tolson C, Carter R, Coulter C, Huygens F, Hargreaves M: Isolation of nontuberculous mycobacteria (NTM) from household water and shower aerosols in patients with pulmonary disease caused by NTM. J Clin Micro 2013, 51:3006-3011.

26. Wallace $R$, lakhiaeva E, Williams M, Brown-Elliott B, Vasireddy $S$, Vasireddy $R$, Lande L, Peterson DD, Sawicki J, Kwait R, Tichenor WS, Turenne C, Falkinham JO 3rd: Absence of Mycobacterium intracellulare and presence of Mycobacterium chimaera in household water and biofilm samples of patients in the United States with Mycobacterium avium Complex respiratory disease. J Clin Micro 2013, 51:1747-1752.

27. Dawson D: Potential pathogen among strains of mycobacteria isolated from house-dusts. Med J Aust 1971, 1:679-681.

28. Resnikov M, Dawson D: Serological investigation of strains of Mycobacterium intracellulare ("Battey" Bacillus) isolated from house-dusts. Med J Aust 1971, 1:682-683.

29. Bolster C, Cook K, Haznedaroglu B, Walker S: The transport of Mycobacterium avium subsp. paratuberculosis through saturated aquifer materials. Lett App/ Microbiol 2009, 48:307-312.

30. Jones R, Jenkins D: Mycobacteria isolated from soil. Can J Microbiol 1965, 11:127-133.

31. livanainen $E$, Martikainen $P$, Katila $M$, Väänänen $P$ : Environmental factors affecting the occurrence of mycobacteria in brook sediments. $J$ Appl Microbiol 1999, 86:673-681.

32. Brooks R, Parker B, Gruft H, Falkinham J 3rd: Epidemiology of infection by nontuberculous mycobacteria. V. Numbers in eastern United States soils and correlation with soil characteristics. Am Rev Respir Dis 1984, 130:630-633.

33. Kazda J: The ecology of mycobacteria. Dordrecht: Springer; 2009.

34. Armstrong R, Imhoff M, Nuttall J, Adcock D, Best F, Chittleborough D, Wilhem N: Identifying, understanding and managing hostile subsoils for cropping. Melbourne: The Profitable Soils Group; 2009.

35. Smith D, Sims B, O'Neill D: Testing and evaluation of agricultural machinery and equipment. Rome: Food and Agriculture Organization of the United Nations; 1994.

36. Kirschner R Jr, Parker B, Falkinham J III: Epidemiology of infection by nontuberculous mycobacteria. Mycobacterium avium, Mycobacterium intracellulare, and Mycobacterium scrofulaceum in acid, brown-water swamps of the southeastern United States and their association with environmental variables. Am Rev Respir Dis 1992, 145:271-275.

37. Falkinham J III, Parker B, Gruft H: Epidemiology of infection by nontuberculous mycobacteria. I. Geographic distribution in the eastern United States. Am Rev Respir Dis 1980, 121:931-937.

38. Olivier K, Weber D, Wallace R Jr, Faiz A, Lee J, Zhang Y, Brown-Elliot BA, Handler A, Wilson RW, Schechter MS, Edwards LJ, Chakraborti S, Knowles MR, Nontuberculous Mycobacteria in Cystic Fibrosis Study Group: Nontuberculous mycobacteria: I: multicenter prevalence study in cystic fibrosis. Am J Respir Crit Care Med 2003, 167:828-834.

39. Thomson R, Tolson C, Sidjabat H, Huygens F, Hargreaves M: Mycobacterium abscessus isolated from municipal water-a potential source of human infection. BMC Infect Dis 2013, 13:241. doi: 10.1186/1471-2334-13-241.

40. Jacobs J, Rhodes M, Sturgis B, Wood B: Influence of environmental gradients on the abundance and distribution of Mycobacterium spp. in a coastal lagoon estuary. App/ Environ Microbiol 2009, 75:7378-7384.

41. Falkinham J III, Norton C, Lechevallier M: Factors influencing numbers of Mycobacterium avium, Mycobacterium intracellulare, and other mycobacteria in drinking water distribution systems. Appl Environ Microbiol 2001, 67:1225-1231.

42. Robinson W: Ecological correlations and the behavior of individuals. Int J Epidemiol 2009, 38(2):337-341.

43. Wakefield J: Multi-level modelling, the ecologic fallacy, and hybrid study designs. Int J Epidemio/ 2009, 38(2):330-336.

44. State of the Climate 2012: [e-book] Canberra: Australian Government Bureau of Meteorology; CSIRO. ; 2012. Available through: http://www.bom.gov.au/ inside/publications.shtml http://www.csiro.au/Outcomes/Climate/ Understanding/ /media8E59FBA4F8A94FE4B84F01E271226316.pdf [Accessed: 12 Nov 2013].

doi:10.1186/1471-2334-14-279

Cite this article as: Chou et al:: A spatial epidemiological analysis of nontuberculous mycobacterial infections in Queensland, Australia. BMC Infectious Diseases 2014 14:279.

\section{Submit your next manuscript to BioMed Central and take full advantage of:}

- Convenient online submission

- Thorough peer review

- No space constraints or color figure charges

- Immediate publication on acceptance

- Inclusion in PubMed, CAS, Scopus and Google Scholar

- Research which is freely available for redistribution 